\title{
ELIPSOIDINIŲ IR NORMALINIŲ AUKŠČIŲ SĄSAJA, TAIKANT KOLOKACIJOS METODĄ
}

\author{
Jonas Skeivalas, Žilvinas Stankevičius \\ Geodezijos ir kadastro katedra, Vilniaus Gedimino technikos universitetas, \\ Sauletekio al. 11, LT-10223 Vilnius-40, Lietuva, el.paštas: gkk@ap.vtu.lt
}

Iteikta 20031215, priimta 20040210

\begin{abstract}
Santrauka. Straipsnyje analizuojami normalinių aukščių prognozės modeliai, sudaryti kolokacijos metodu, itraukiant GPS matavimais nustatytus elipsoidinius aukščius. Prognozės modeliams sudaryti išvedamos lygčių sistemos, taikant atitinkamos eilès daugianarius. Optimalaus prognozės modelio parametrų reikšmès gaunamos pagal statistinius elipsoidinių ir normalinių aukščiu nuokrypius identiškuose taškuose, keičiant daugianarių eilę ir elipsoidinių bei normaliniu aukščių svorių matricos elementus. Pateikiamos formulès elipsoidinių aukščiu klaidu itakai prognozès modelio parametrų bei normalinių aukščių tikslumui ịvertinti.
\end{abstract}

Raktažodžiai: elipsoidiniai ir normaliniai aukščiai, prognozavimas, kolokacija, kovariacija, GPS, geoidas.

\section{Ivadas}

Geodezijos praktikoje remiamasi niveliavimo metodu nustatytais normaliniais aukščiais. Niveliavimo procedūroms atlikti tenka skirti nemažai lěšų ir laiko. Todèl atliekami îvairūs moksliniai ir praktiniai tyrimai siekiant susieti normalinius bei elipsoidinius aukščius, nustatomus GPS (globalinių padèties nustatymo sistemu) metodu [1-4]. GPS metodas ekonomiškesnis laiko požiūriu ir nepriklauso nuo veiksnių, turinčių itakos niveliavimo procesui. Elipsoidiniai aukščiai nustatomi pagal klaidas, kurių reikšmès esti keletas centimetrų. Toks tikslumas pakankamas kartografiniuose bei inžineriniuose darbuose. Kadangi normaliniai aukščiai skaičiuojami nuo kvazigeoido paviršiaus, kyla nauja problema - elipsoidinius aukščius transformuoti i normalinių aukščiu sistemą. Tokią aukščių sistemų tarpusavio sąsają būtų imanoma pakankamu tikslumu realizuoti, jei būtų sudarytas pakankamai detalus ir tikslus kvazigeoido modelis. Tačiau tokiam kvazigeoido modeliui sudaryti reikia atlikti pakankamai daug ir tiksliu gravimetrinių matavimu $[2,3]$.

Šiame straipsnyje pateikiamas normalinių ir elipsoidinių aukščių sąsajos metodas, taikant atitinkamus prognozavimo modelius [5-8].

Prognozavimo modelių parametrų reikšmès apskaičiuojamos kolokacijos metodu, naudojant identiškuose taškuose išmatuotus normalinius ir elipsoidinius aukščius. Apskaičiuotos parametrų reikšmès tikslinamos taikant Kalmano filtravimo procedūrą.

\section{Prognozavimo modelio parametrų reikšmių skaičiavimas}

Prognozavimo modeliams sudaryti taikysime tiesinių lygčiu sistemą, kurios kiekvienos lygties pagrindinès dedamosios yra sisteminè dalis, arba trendas, ir atsitiktiné dalis, arba kolokacinis signalas. Trendą apibrèšime tam tikrais nežinomaisiais, vadinamais parametrais. Kaip kolokacinius signalus naudosime normalinius aukščius, kurie yra atsitiktiniai dydžiai, nes išmatuojami su tam tikromis klaidomis, turinčiomis sisteminę ir atsitiktinę dedamąsias.

Prognozavimo modelio parametrų reikšmėms skaičiuoti taikysime tiesini modelị, užrašomą lygčiu sistema:

$$
\left.\begin{array}{l}
\tilde{H}_{e}=(A \mid U) \tilde{T}=A \tilde{T}_{x}+U \tilde{H}_{n} \\
\tilde{H}_{n}=\tilde{H}_{n}
\end{array}\right\},
$$

čia $\tilde{T}=\left(\tilde{T}^{T}, \tilde{H}_{n}^{T}\right)^{T}-$ blokinis parametrų vektorius, $\tilde{H}_{e}-$ išlygintų elipsoidinių aukščiuc vektorius, $\tilde{T}_{x}-$ determinuotuju parametrų išlygintų reikšmių vektorius, $\tilde{H}_{n}-$ išlygintų normalinių aukščių vektorius; $A, U-$ atitinkamų lygčių koeficientų matricos.

Tiesinio modelio (1) parametru ir kolokaciniu signalų išlygintų reikšmių vektoriai $\tilde{T}_{x}$ ir $\tilde{H}_{n}$ gaunami apdorojus mažiausiujuc kvadratų metodu identiškuose taškuose išmatuotų elipsoidinių $H_{e}$ bei normalinių aukščių $H_{n}$ ir vektorių reikšmes.

Lygčių sistemą (1) rašome pataisų lygčių sistemos pavidalu:

$$
\left.\begin{array}{l}
V_{e}=A \tilde{T}_{x}+U \tau_{n}+U H_{n}-H_{e} \\
V_{n}=\tau_{n}
\end{array}\right\},
$$

čia $V_{e}=\tilde{H}_{e}-H_{e}, \tau_{n}=\tilde{H}_{n}-H_{n}$.

Sistemą (2) galime parašyti blokiniu pavidalu: 


$$
V=\left(\begin{array}{cc}
A & U \\
0 & E
\end{array}\right) \tau+L=A_{0} \tau+L
$$

čia $\tau=\left(\tilde{T}_{x}^{T}, \tau_{n}^{T}\right)^{T}, \quad L=\left(L_{1}^{T}, 0\right)^{T}, \quad L_{1}=U H_{n}-H_{e}, \quad E-$ vienetinè matrica; $V=\left(V_{e}^{T}, V_{n}^{T}\right)^{T}, A_{0}=\left(\begin{array}{cc}A & U \\ 0 & E\end{array}\right)$.

Pataisų lygčių sistemai (3) spręsti taikoma mažiausiuju kvadratų metodo sąlyga, darant prielaida, kad veikia tik atsitiktinès atitinkamų dydžių klaidos:

$$
\Phi=V_{e}^{T} P_{e} V_{e}+V_{n}^{T} P_{n} V_{n}=\min
$$

čia $P_{e}, P_{n}-$ išmatuotų elipsoidinių ir normalinių aukščių svorių matricos.

Parametrų vektorius $\tau$ skaičiuojamas iš normalinių lygčių sistemos:

$$
N \tau+\omega=0
$$

ir $\tau=-N^{-1} \omega$,

čia $N=A_{0}^{T} P A_{0}-$ normalinių lygčių koeficientų matrica, $\omega=A_{0}^{T} P L-$ laisvujų narių vektorius.

Svorių matricos $P$ ir laisvujų narių vektoriaus $\omega$ išraiškos:

$$
\begin{aligned}
& P=\left(\begin{array}{ll}
P_{e} & \\
& P_{n}
\end{array}\right), \\
& \omega=\left(\begin{array}{ll}
A^{T} & P_{e} \\
U^{T} & P_{e}
\end{array}\right) L_{1} .
\end{aligned}
$$

Normalinių lygčiu koeficientų matricą $N$ galima užrašyti blokiniu pavidalu:

$$
\begin{aligned}
& N=\left(\begin{array}{ll}
N_{11} & N_{12} \\
N_{21} & N_{22}
\end{array}\right)=\left(\begin{array}{ll}
A & U \\
0 & E
\end{array}\right)^{T}\left(\begin{array}{ll}
P_{e} & \\
& P_{n}
\end{array}\right)\left(\begin{array}{cc}
A & U \\
0 & E
\end{array}\right)= \\
& =\left(\frac{A^{T} P_{e} A}{U^{T} P_{e} A} \mid \frac{A^{T} P_{e} U}{U^{T} P_{e} U+P_{n}}\right) .
\end{aligned}
$$

Apskaičiuotų parametrų vektoriaus $\tilde{T}$ kovariacijų matrica $K_{\tilde{T}}$ gaunama mažiausiujų kvadratų metodu pagal formulę:

$$
K_{\tilde{T}}=\sigma_{0}^{2} N^{-1}=\sigma_{0}^{2}\left(\begin{array}{ll}
Q_{11} & Q_{12} \\
Q_{21} & Q_{22}
\end{array}\right),
$$

čia $\sigma_{0}$ - matavimo rezultato, kurio svoris lygus vienetui, standartinis nuokrypis. Jis nustatomas iš formulès:

$$
\sigma_{0}^{2}=\frac{1}{n-k} V^{T} P V
$$

čia $n$ - pataisų lygčių skaičius, $k$ - parametru (nežinomuju) skaičius.

Išlygintų parametrų vektoriaus $\tilde{T}$ reikšmė gaunama iš formulès [9]:

$$
\tilde{T}=\left(\begin{array}{c}
\tilde{T}_{x} \\
\tau_{n}
\end{array}\right)=-\left(\begin{array}{c}
Q_{11} A^{T} P_{e}+Q_{12} P_{e} \\
Q_{21} A^{T} P_{e}+Q_{22} P_{e}
\end{array}\right) L_{1}
$$

Vektoriaus $\tilde{T}$ dedamujų $\tilde{T}_{x}$ ir $\tau_{n}$ išraiškas galima užrašyti kitokiu pavidalu [5]:

$$
\begin{aligned}
& \tilde{T}_{x}=\left\{A^{T}\left(U P_{n}^{-1} U^{T}+P_{e}^{-1}\right)^{-1} A\right\}^{-1} \times \\
& \times A^{T}\left(U P_{n}^{-1} U^{T}+P_{e}^{-1}\right)^{-1} L_{1}, \\
& \tau_{n}=-P_{n}^{-1} U^{T}\left(U P_{n}^{-1} U^{T}+P_{e}\right)^{-1}\left(L_{1}+A \tilde{T}_{x}\right) .
\end{aligned}
$$

Išlygintų parametrų vektoriaus $\tilde{T}_{x}$ ir normalinių aukščių $\tilde{H}_{n}$ kovariacijų bei jų tarpusavio kovariacijų matricas gauname blokinių matricų pavidalu iš išraiškos (7):

$$
\left.\begin{array}{l}
K_{\tilde{T}_{x}}=\sigma_{0}^{2} Q_{11} \\
K\left(\begin{array}{c}
\tilde{T}_{x} \\
\tilde{H}_{n}
\end{array}\right)=\sigma_{0}^{2} Q_{12} \\
K\left(\begin{array}{c}
\tilde{H}_{n} \\
\tilde{T}_{x}
\end{array}\right)=K^{T}\left(\begin{array}{c}
\tilde{T}_{x} \\
\tilde{H}_{n}
\end{array}\right)=\sigma_{0}^{2} Q_{21} \\
K_{\tilde{H}_{n}}=K_{\tau_{n}}=\sigma_{0}^{2} Q_{22}
\end{array}\right\} .
$$

Vektoriu $\tilde{T}_{x}$ ir $\tilde{H}_{n}$ tarpusavio kovariacijų matrica $K\left(\begin{array}{c}\tilde{T}_{x} \\ \tilde{H}_{n}\end{array}\right)$ parodo parametru vektoriaus $\tilde{T}_{x}$ klaidu itaką vektoriaus $\tilde{H}_{n}$ tikslumui. Nustatysime, kokią titaką vektoriaus $\tilde{H}_{n}$ tikslumui turi vektoriaus $\tilde{H}_{e}$ matavimu klaidos, t. y. gausime vektorių $\tilde{H}_{n}$ ir $\tilde{H}_{e}$ tarpusavio kovariaciju matricos išraišką $K\left(\begin{array}{c}\tilde{H}_{n} \\ \tilde{H}_{e}\end{array}\right)$. Taigi galime parašyti:

$$
\begin{aligned}
& K\left(\begin{array}{c}
\tilde{H}_{e} \\
\tilde{T}
\end{array}\right)=K\left(\begin{array}{c}
\tilde{H}_{e} \\
\tilde{T}_{x}
\end{array}\right) \mid K\left(\begin{array}{c}
\tilde{H}_{e} \\
\tilde{H}_{n}
\end{array}\right)= \\
& =M\left\{\left(\tilde{H}_{e}-M \tilde{H}_{e}\right)(\tilde{T}-M \tilde{T})^{T}\right\}=M\left\{\delta \tilde{H}_{e} \cdot(\delta \tilde{T})^{T}\right\}= \\
& =M\left\{(A U) \delta \tilde{T} \cdot(\delta \tilde{T})^{T}\right\}=(A U) K_{\tilde{T}},
\end{aligned}
$$

čia $M-$ vidurkio (matematinès vilties) simbolis, $\delta \tilde{H}_{e}, \delta \tilde{T}-$ išlygintų elipsoidinių aukščių ir parametrų atsitiktinių klaidų vektoriai.

Taikydami kovariacijų matricos $K_{\tilde{T}}$ išraišką (7), formulę (12) parašome tokiu pavidalu:

$$
\begin{aligned}
& K\left(\begin{array}{c}
\tilde{H}_{e} \\
\tilde{T}
\end{array}\right)=\sigma_{0}^{2}(A U)\left(\begin{array}{ll}
Q_{11} & Q_{12} \\
Q_{21} & Q_{22}
\end{array}\right)= \\
& =\sigma_{0}^{2}\left\{A Q_{11}+U Q_{21} \mid A Q_{12}+U Q_{22}\right\} .
\end{aligned}
$$


Gauname:

$$
K\left(\begin{array}{c}
\tilde{H}_{e} \\
\tilde{T}_{x}
\end{array}\right)=A Q_{11}+U Q_{21}
$$

ir

$$
K\left(\begin{array}{l}
\tilde{H}_{e} \\
\tilde{H}_{n}
\end{array}\right)=A Q_{12}+U Q_{22} .
$$

Išlygintų elipsoidinių aukščių $\tilde{H}_{e}$ kovariacijų matricą $K_{\widetilde{H}_{e}}$ galima išreikšti tokiu pavidalu:

$$
\begin{aligned}
& K_{\tilde{H}_{e}}=(A U) K_{\widetilde{T}}(A U)^{T}=A Q_{11} A^{T}+U Q_{21} A^{T}+ \\
& +A Q_{12} U^{T}+U Q_{22} U^{T} .
\end{aligned}
$$

\section{Prognozès modelio formavimas}

Daroma prielaida, kad tam tikros teritorijos kvazigeoido paviršiaus kaita atitinka pasirinktą prognozès modelį, kai taikomas apskaičiuotu parametrų reikšmių vektorius $\tilde{T}_{x}$. Tokiu atveju normalinių aukščių vektoriui skaičiuoti galima taikyti prognozès formulę

$$
H_{n S}=H_{e}-A_{S} \tilde{T}_{x}
$$

čia $H_{e}$ - tam tikroje geodezinio tinklo dalyje išmatuotu elipsoidinių aukščių vektorius; $A_{S}-$ prognozès lygčių daugianarių koeficientų matrica, sudaroma taikant prognozavimo taškų koordinates.

Prognozuojamų normalinių aukščių vektoriaus $H_{n S}$ tikslumas ivertinamas kovariacijų matrica $K_{H_{n S}}$, gaunama remiantis matematinès statistikos dèsniais:

$$
K_{H_{n S}}=\left\{\left(H_{n S}-M H_{n S}\right)\left(H_{n S}-M H_{n S}\right)^{T}\right\} .
$$

Toliau galime parašyti:

$$
\begin{aligned}
& K_{H_{n S}}=M\left\{\left(\delta H_{e}-A_{S} \delta \tilde{T}_{x}\right)\left(\delta H_{e}-A_{S} \delta \tilde{T}_{x}\right)^{T}\right\}= \\
& =K_{H_{e}}-K\left(\begin{array}{c}
H_{e} \\
\tilde{T}_{x}
\end{array}\right) A_{S}^{T}-A_{S} K\left(\begin{array}{c}
\tilde{T}_{x} \\
H_{e}
\end{array}\right)+A_{S} K_{\tilde{T}_{x}} A_{S}^{T} .
\end{aligned}
$$

GPS metodu išmatuotų elipsoidinių aukščiu kovariaciju matricos $K_{H_{e}}$ ivvertis $K_{H_{e}}^{\prime}$ nustatomas apdorojant GPS matavimų rezultatus.

Parametru vektorius $\tilde{T}_{x}$ ir jo kovariaciju matrica $K_{\tilde{T}_{x}}$ (11) priklauso nuo kvazigeoido paviršiaus ir nuo vektoriaus $H_{e}$. Kadangi prognozuojamų taškų srityje kovariaciju matricos $K\left(\begin{array}{c}H_{e} \\ \tilde{T}_{x}\end{array}\right)=K^{T}\left(\begin{array}{c}\tilde{T}_{x} \\ H_{e}\end{array}\right)$ apskaičiuoti neịmanoma, darome prielaidą, kad ji mažai skiriasi nuo atliekant kolokacijos procedūras nustatytos kovariaciju matricos $K\left(\begin{array}{c}\tilde{H}_{e} \\ \tilde{T}_{x}\end{array}\right)$, apskaičiuojamos pagal formulę (14). Tokią prielaidą būtų teisinga daryti kalbant apie teritorijas, kuriose gravitacijos laukas yra reguliarus. Tokia teritorija galima laikyti Lietuvos teritoriją.

Teorinius samprotavimus iliustruosime praktiniais skaičiavimais. Tam tikslui panaudosime Lietuvos 1-osios klasès vertikaliojo tinklo matavimu rezultatus ir nustatytus šio tinklo reperių elipsoidinius aukščius bei jų koordinates LKS 94 sistemoje.

1 lentelè. Parametrų vektoriaus $T_{x}$ komponenčių reikšmès Table 1. Values of the components of the vector $T_{x}$

\begin{tabular}{|l|r|r|}
\hline $\begin{array}{l}\text { Parametro } \\
\text { simbolis }\end{array}$ & \multicolumn{1}{c|}{$\begin{array}{c}\text { 5-iu parametru } \\
\text { variantas }\end{array}$} & \multicolumn{1}{c|}{$\begin{array}{c}\text { 9-iu parametru } \\
\text { variantas }\end{array}$} \\
\hline$T_{1 x}$ & 0,000066922000000 & $-0,007508500000000$ \\
$T_{2 x}$ & 0000005248400000 & 0,053372000000000 \\
$T_{3 x}$ & $-0,000000000039583$ & 0,000000014540000 \\
$T_{4 x}$ & $-0,000000000037936$ & $-0,000000055533000$ \\
$T_{5 x}$ & $-0,000000000008095$ & $-0,000000095028000$ \\
$T_{6 x}$ & & $-0,000000000000007$ \\
$T_{7 x}$ & & 0,000000000000008 \\
$T_{8 x}$ & & 0,000000000000042 \\
$T_{9 x}$ & & 0,000000000000053 \\
\hline
\end{tabular}

Prognozavimo modelio (17) parametrų vektoriaus $T_{x}$ reikšmės skaičiuotos dviem variantais: 5-ių ir 9-ių komponenčių. Vektoriaus $T_{x}$ komponentès buvo nustatytos apdorojus mažiausiujų kvadratų metodu 50-ies identišku tašku (žr. pav.) elipsoidinių aukščiu $H_{e}$ ir normalinių aukščiu $H_{n}$ matavimais gautas reikšmes. Tam tikslui taikyta lygčių sistema (3), kai $U=E$ ir

$$
\begin{aligned}
& A_{i}=x_{i} t_{1 x}+y_{i} t_{2 x}+x_{i}^{2} t_{3 x}+y_{i}^{2} t_{4 x}+x_{i} y_{i} t_{5 x}, \\
& A_{i}=x_{i} t_{1 x}+y_{i} t_{2 x}+x_{i}^{2} t_{3 x}+y_{i}^{2} t_{4 x}+x_{i} y_{i} t_{5 x}+ \\
& +x_{i}^{3} t_{6 x}+y_{i}^{3} t_{7 x}+x_{i}^{2} y_{i} t_{8 x}+x_{i} y_{i}^{2} t_{9 x},
\end{aligned}
$$

čia $A_{i}-$ matricos $A$ blokai. Formulèje (20) naudojami 5, o formulèje (21) - 9 parametrai. Apskaičiuotu parametru reikšmès parodytos 1 lentelèje.

Taikydami gautąsias parametru $t_{i x}$ reikšmes ir prognozès formulę (17) nustatome prognozuojamąsias 13-os kontrolinių taškų normalinių aukščių $H_{n S}$ reikšmes (2 ir 3 lentelès; pav. - pavaizduota kvadratèliais). 2 ir 3 lentelèse duoti prognozinių normalinių aukščių $H_{n S}$ nuokrypiai $\delta H$ nuo normalinių aukščiu $H_{n}$, nustatytų precizinio niveliavimo metodu.

Prognozinių normalinių aukščių $H_{n S}$ tikslumas ivertintas skaičiuojant standartinių nuokrypių îverčius: 


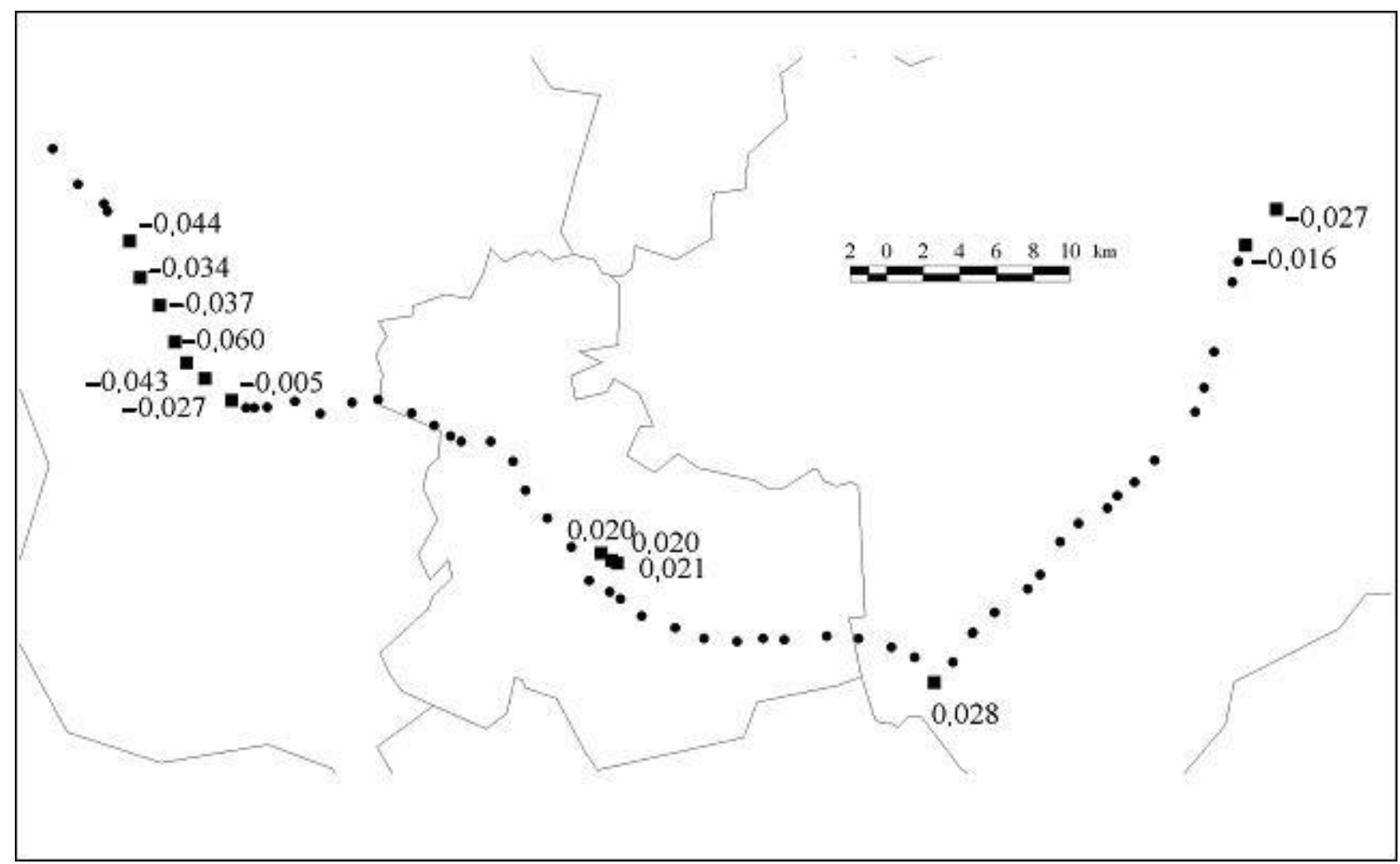

GPS ir vertikaliojo tinklo sąsajų schema

The diagram of the GPS and vertical network connections

$$
m_{H}=\sqrt{\frac{\sum_{1}^{13}(\delta H)^{2}}{n-1}} .
$$

$m_{H, 5}=0,034 \mathrm{~m}$, o taikydami 9-iu parametru modeli $m_{H, 9}=0,24 \mathrm{~m}$. Nustatyta, kad normaliniu aukščiu $H_{n}$ svoriu itaka prognozès modelio parametru vektoriaus reikšmių tikslumui nedidelè.

2 lentelè. Normalinių aukščių prognozavimas, taikant 5-ių parametrų modelị Table 2. Prognosis of the normal heights applying the model of 5 parameters

\begin{tabular}{|c|c|c|c|c|}
\hline Taško Nr. & $\begin{array}{c}\text { Elipsoidiniai } \\
\text { aukščiai } H_{e}, \mathrm{~m}\end{array}$ & $\begin{array}{c}\text { Normaliniai } \\
\text { aukščiai } H_{n}, \mathrm{~m}\end{array}$ & $\begin{array}{c}\text { Prognozuojamieji } \\
\text { normaliniai aukščiai } H_{n s}, \\
\mathrm{~m}\end{array}$ & $\delta H=H_{n}-H_{n s}, \mathrm{~m}$ \\
\hline $52 \mathrm{~V} 10045$ & 180,481 & 153,577 & 153,621 & $-0,044$ \\
\hline $52 \mathrm{~V}-0551$ & 166,782 & 139,867 & 139,901 & $-0,034$ \\
\hline $52 \mathrm{~V} 10058$ & 159,572 & 132,643 & 132,680 & $-0,037$ \\
\hline $51 \mathrm{~V}-7639$ & 157,136 & 130,166 & 130,226 & $-0,060$ \\
\hline $51 \mathrm{~V} 10064$ & 159,165 & 132,203 & 132,246 & $-0,043$ \\
\hline 51V10061 & 151,661 & 124,713 & 124,740 & $-0,027$ \\
\hline $51 \mathrm{~V}--317$ & 160,440 & 133,511 & 133,516 & $-0,005$ \\
\hline $51 \mathrm{~V} 15101$ & 127,750 & 100,936 & 100,916 & 0,020 \\
\hline $51 \mathrm{~V} 15102$ & 122,360 & 95,547 & 95,527 & 0,020 \\
\hline $51 \mathrm{~V} 15103$ & 124,300 & 97,489 & 97,468 & 0,021 \\
\hline $61 \mathrm{~V}-0398$ & 159,946 & 133,254 & 133,226 & 0,028 \\
\hline $62 \mathrm{~V}-0119$ & 153,319 & 127,096 & 127,112 & $-0,016$ \\
\hline $62 \mathrm{~V} 10027$ & 154,907 & 128,722 & 128,749 & $-0,027$ \\
\hline
\end{tabular}


3 lentelè. Normalinių aukščių prognozavimas, taikant 9-ių parametrų modeli

Table 3. Prognosis of the normal heights applying the model of 9 parameters

\begin{tabular}{|l|c|c|c|c|}
\hline Taško Nr. & $\begin{array}{c}\text { Elipsoidiniai } \\
\text { aukščiai } H_{e}, \mathrm{~m}\end{array}$ & $\begin{array}{c}\text { Normaliniai } \\
\text { aukščiai } H_{n}, \mathrm{~m}\end{array}$ & $\begin{array}{c}\text { Prognozuojamieji } \\
\text { normaliniai aukščiai } H_{n s}, \\
\mathrm{~m}\end{array}$ & $\delta H=H_{n}-H_{n s}, \mathrm{~m}$ \\
\hline $52 \mathrm{~V} 10045$ & 180,481 & 153,577 & 153,387 & 0,190 \\
$52 \mathrm{~V} 0551$ & 166,782 & 139,867 & 139,643 & 0,224 \\
$52 \mathrm{~V} 10058$ & 159,572 & 132,643 & 132,423 & 0,220 \\
$51 \mathrm{~V} 7639$ & 157,136 & 130,166 & 129,977 & 0,189 \\
$51 \mathrm{~V} 10064$ & 159,165 & 132,203 & 132,008 & 0,195 \\
$51 \mathrm{~V} 10061$ & 151,661 & 124,713 & 124,513 & 0,200 \\
$51 \mathrm{~V} 317$ & 160,440 & 133,511 & 133,304 & 0,207 \\
$51 \mathrm{~V} 15101$ & 127,750 & 100,936 & 100,692 & 0,244 \\
$51 \mathrm{~V} 15102$ & 122,360 & 95,547 & 95,303 & 0,244 \\
$51 \mathrm{~V} 15103$ & 124,300 & 97,489 & 97,244 & 0,245 \\
$61 \mathrm{~V} 0398$ & 159,946 & 133,254 & 133,009 & 0,245 \\
$62 \mathrm{~V} 0119$ & 153,319 & 127,096 & 126,861 & 0,235 \\
$62 \mathrm{~V} 10027$ & 154,907 & 128,722 & 128,429 & 0,293 \\
\hline
\end{tabular}

\section{Išvados}

1. Rekomenduojamos formulès (17), (19) normaliniu aukščiu prognozès modeliui sudaryti ir tikslumui ivertinti, taikant GPS metodu išmatuotus elipsoidinius aukščius.

2. Prognozès modelio parametru reikšmès nustatomos apdorojus kolokacijos metodu identiškuose taškuose išmatavus gautas elipsoidinių ir normaliniu aukščiu reikšmes. Kadangi parametru reikšmès priklauso nuo nagrinejjamos teritorijos kvazigeoido paviršiaus kaitos, tikslinga modelio parametru reikšmes nustatyti tam tikrų regionų, kuriuose kvazigeoido paviršiaus kaita yra reguliari.

3. Prognozès modelio tikslumas ivertintas dviem analizès variantais: taikant 5-osios ir 9-osios eiliu daugianarių koeficientų matricas. Normalinių aukščiu reikšmès tikslesnès taikant 5-osios eilès daugianarius. Normaliniu aukščiu reikšmių standartinių nuokrypiu iverčiai maždaug atitinka GPS metodu nustatytu elipsoidinių aukščiu standartinių nuokrypių ivverčius.

\section{Literatūra}

1. Łyszkowicz, S. Interpolation techniques to convert GPS ellipsoid heights to elevations. Geodesy and Cartography (Geodezija ir kartografija), Vol XXVIII, No 3. Vilnius: Technika, 2002, p. 105-107.
2. Paršeliūnas, E.; Sacher, M.; Ihde, J. Preparation of Lithuanian levelling network data for united European levelling network. Geodesy and Cartography (Geodezija ir kartografija), Vol XXVI, No 4. Vilnius: Technika, 2000, p. 171-186.

3. Denker, H.; Paršeliūnas, E. Evaluation of the European gravimetric geoid / Quasigeoid EGG97 over the Lithuanian territory. Geodesy and Cartography (Geodezija ir kartografija), Vol XXV, No 4. Vilnius: Technika, 1999, p. 167-173.

4. Ardlan, A.; Grafarend, E.; Kakkuri, J. National height datum, the Gauss-Listing geoid level value $W_{0}^{*}$ and its time variation $W_{0}^{*}$ (Baltic Sea Level Project: epochs 1990.8, 1993.8, 1997.4). Journal of Geodesy, Vol 76, No 1. Berlin: Springer Verlag, 2002, p. 1-28.

5. Koch, K-R. Einführung in die Bayes-Statistik. Berlin Heidelberg: Springer-Verlag, 2000. 225 S.

6. Moritz, H. Advanced Physical Geodesy. Karlsruhe: H. Wichmann Verlag, 1980. 390 S.

7. Wolf, H. Zur Grundlegung der Kollokationsmethode. Z. F. Vermessungswessen, 1977, Heft 6. Stuttgart, Verlag K. Witwer, p. 17-24.

8. Fisher, B.; Hegland, M. Collocation, Filtering and Nonparametric Regression, Part 1. Z. F. Vermessungswessen, 1999, Helf 1. Stuttgart, Verlag, K. Witwer, p. 17-24.

9. Skeivalas, J. Treatment of correlated geodetic measurements results (Koreliuotų geodeziniu matavimu rezultatų apdorojimas). Vilnius: Technika, 1995. 272 p. 